\title{
Corporate Code of Ethics and Reporting Wrongdoing in Private Sector Organizations in Malaysia
}

\author{
Zeinab Amini Yekta \\ School of Management, Universiti Sains Malaysia \\ Penang Island 11800, Malaysia \\ E-mail: zeinabay@gmail.com \\ Associate Professor Dr. Zainal Ariffin Ahmad \\ Graduate School of Business, Universiti Sains Malaysia \\ Penang Island 11800, Malaysia \\ E-mail: drzaba2001@yahoo.com \\ Ajindar Kaur \\ Universiti Sains Malaysia, School of Humanities \\ Penang Island 11800, Malaysia \\ E-mail: ajindarkb@yahoo.com
}

\begin{abstract}
With rapid changes in technology and the borderless global environment, organizations need to have ethical guiding principles. Malaysia as a developing country needs to focus on and be aware of the ethics codes and guidelines in organizations as well as minimize wrongdoings. Ethical behaviors which should be emulated need to be portrayed instead of negative behaviors being emphasized. Strategic implementation and commitment to organizational change with proper communication channels and having ethical safeguards in place are expected to enhance the application of ethical guidelines. Effective communication is important for successful implementation of code of ethics programs which will ultimately improve reporting wrongdoing in organizations. The results show that, employee relationship is the most important determinant of reporting wrongdoing. Having ethical codes and guidelines alone without being effective will not benefit the organization. It indicate that to be effective when having code of ethics and reporting wrongdoing, the organization must invest time and effort in building good strong employee relationships.
\end{abstract}

Keywords: Reporting wrongdoing, Corporate code of ethics, Employee relationship, Communication

\section{Introduction}

The Prime Minister's continued call to reinforce ethical policies and applications in Ninth Malaysia plan and interest in Transparency rankings, hence Malaysia needs to focus on ethics codes and guidelines in the organizations and minimize wrongdoings.

Though extensive studies have been done in US and Ireland and Canada, literature on the existence and effective application of ethical codes in practice is limited if any and not available in the local context .Studies have been done elsewhere and thus we cannot generalize to our local context. This research hopes to provide useful input into the development of human resource in the country.

With the government's emphasis on developing human capital in the $9^{\text {th }}$ Malaysia Plan, it has become even more important than before to address the issue of effective application of corporate code of ethics in this rapidly changing global economy. The labor market being mobile and borderless today poses new challenges to organizations today. As Malaysia also is an investment hub, they have many Multinational companies and the impact on these need to be studied especially in the local context. The importance of having these codes applied for the company and society is very important so that all three i.e., the organization, the individual and the company are protected. This research will take into account the local values and culture of the Malaysian people. 
This research hopes to provide some insight to the application of corporate ethics codes and ethical practices in the local population and their impact on reporting wrongdoing in organizations. With rapid changes in technology and the borderless global environment, organizations need to have ethical guiding principles acceptable to all societies with different cultural pattern.

\section{Review of Related Literature}

Many organizations have a code of conduct to guide the executives and employees as to the norms expected from them, but the organization's mission and vision statements may or may not give an indicator of the ethical dimension of the organization. Donaldson (1989) argues that for all decisions and actions in business there is an ethical dimension, however in the process of setting vision, ethical issues poorly discussed.

According to Blau (1964) the Social Exchange theory is consider as an economic model of human behavior, where employees' desires to maximize benefits and minimize defeats support the interactions between them and the organization or its agents.

Most corporations now have formal or written ethics policies that are provided to their employees. Informal codes of ethics were used to guide ethical decision long before formal codes of ethics were drawn up. Formal codes need to be consistent with long-standing informal codes. Peterson (2003) mentions that from the employee's point of view, an ethical conflict usually occurs when employees feel pressured by their coworkers or supervisors.

\section{Ethics Safeguards and Practices}

Many previous studies implies, recently great number of organizations have certain codes of ethics as guides for managers, supervisors and employees (Sims, 2000; Murphy, 1995; Embse, Desai and Desai, 2004). However some other researchers think that kind of ethical codes and policies are not enough to result ethical behavior (Embse, Desai and Desai, 2004).

According to Embse, Desai and Desai (2004), the expectations of supervisor have an impact on the relationship between ethics codes and consequent behavior, satisfaction and commitment. In addition, in terms of enhancing awareness of the code, the usage of metaphors should be effective. It was found that high ethical compliance organizations also exercised a larger number of ethical safeguards which was supported by running ANOVA test, therefore companies with adequate ethical safeguards can apply their ethical codes and policies more effectively than companies with fewer safeguards.

Embse, Desai and Desai (2004) used a combination of the following seven dimensions of ethics safeguards in their research and they were found to be interdependent and mutually reinforcing, the following are:

- A formal code of ethics,

- A value statement or credo,

- Written general ethics policies,

- Written specific ethics policies,

- A strong cohesive ethical culture,

- $\quad$ Ethical training in place and available, and

- $\quad$ Ready access to ethical code or guidelines when needed.

Ethical practices varied among industries; in addition defense related organizations were found to have a larger number of ethics safeguards. Companies which had more safeguards also applied their ethical codes and policies more effectively than companies with lesser ethical safeguards; moreover the non public organizations were more effective in applying ethical policies as they had a higher number of ethical safeguards and ethical practices were actually carried out (Embse, Desai and Desai, 2004).

In Embse, Desai and Desai (2004) study, ethical practices were measured by using:

- Electronic communication,

- Employee relationships,

- $\quad$ Staffing,

- Quality and productivity,

- $\quad$ Ethical dilemmas,

- $\quad$ Reporting wrongdoing, 
- Legal matters,

- Safety and health,

- Communications,

- $\quad$ Customers, and

- Organizational priorities

O'Dwyer and Madden (2006) used a comprehensive questionnaire to investigate the incidence, content and enforcement of codes of conduct among top 1000 companies in Ireland. From the research it was found that the overall usage of codes of conduct had increased significantly from the years 1995 until 2000 but they mainly focused on employee and company protection and not society protection.

Sims (2000) examined the relationship among lying, supervisory expectations, job satisfaction and commitment. He found, satisfaction and commitment may also be significant factors in the linkage.

The study among ethical policy compliance found that factors such as personal values, fear of discipline and organization loyalty helped explain code compliance; in contrast self-interest, dissatisfaction and environment were reasons for non-compliance (Schwartz, 2001).

\section{Corporate Codes of Ethic and Wrongdoing}

In the study of the evolution and development of the codes, it has been indicated code of ethics was used in different cultures and in different context. According to Farrell, Cobbin and Farrell (2002) codes were found to be inspirational, prescriptive and educational type. Rashid, Sambasivan and Rahman (2004) investigated whether organizational culture has an impact on attitudes towards organizational change in Malaysia. The researchers used a structured, self administered questionnaire and found that there is association between organizational culture and the affective, cognitive and behavioral tendency of attitudes towards change. Different types of culture had different levels of acceptance towards organizational change meaning some cultures facilitate the acceptance of change more readily than others.

Wrongdoing literary define as improper behavior or action, Under the Policy, The act of reporting wrong doing refers to:

- A violation of any law or regulation; or

- $\quad$ Misuse of public funds or assets; or

- Gross mismanagement; or

- A substantial and specific danger to the life, health and safety of Canadians or the environment; or

- $\quad$ Reprisal resulting from good faith disclosures of wrongdoing.

In research conducted by Smith (2006), it was found that the creation and use of the corporate code of ethics had provided the companies with an avenue to declare publicly their commitment to good ethics, by ensuring compliance but did not look at the larger issues of right and wrong.

Emphasizing ethics must be communicated top down, research conducted by Wells and Spinks (1996) found that the code of ethics as well as upper-level management support of the code must be communicated clearly to all persons in the organization which resulted effectively support from everyone in the organization .The role of individuals in implementing and following the code must also is vital and need more focus.

It is also important to indicate ways in which the code should not be violated. Ethical behaviors which should be emulated need to be portrayed instead of negative behaviors being emphasized. Effective communication is important for successful implementation of code of ethics programs which will ultimately improve reporting wrongdoing in organizations.

\section{Theoretical Framework}

Based on the given background, Theoretical framework is shown in Figure 1.

Established upon the above theoretical framework, we would like to posit the following hypotheses:

H1: The existence of a formal code of ethics increases tendency of reporting wrongdoing in organizations.

$\mathrm{H} 2$ : Existence of strong ethical culture increases reporting of wrongdoing.

H3: Employee relationships positively affect reporting wrongdoing in organizations.

H4: Effective enforcement regulations and compliance mechanisms increase reporting wrongdoing 
H5: Effective communication increases the incidence of reporting wrongdoing in organizations.

\section{Research Methodology}

The nature of this study was analytical where the variables to be measured were reporting wrongdoing as the dependent variables and ethical culture, employee relationship, compliance and communication as the independent variables.

\subsection{Participants and Procedure}

The population of study covers randomly selected employees in middle manager position in Penang and Kedah Convenience sampling was used to obtain the respondents. A sample of 105 employees were selected and given a set of questionnaire each and all were returned.

This study was conducted using primary data where questionnaires were prepared and distributed to private sector employees.

\subsection{Measures}

measures of this study were adapted from a study by Embse, Desai and Desai (2004) which was undertaken in the US, The original questionnaire was designed to measure eleven areas of ethical practice namely: electronic communication; employee relationships; staffing; quality and productivity; ethical dilemmas; reporting wrong-doing; legal matters; safety and health; communications; customers; and organizational priorities, however for the mean of this study we omitted some variables.

Current study questionnaires were designed to measure the impact of variables: ethical codes, ethical culture, employee communication, compliance on level of reporting wrongdoing in private sector organizations. The questionnaires consist of two different sections. Section A consists of statements on the factors that lead to the reporting wrongdoing. It comprises of 23 questions covering 6 variables and the questionnaire was delivered using convenience sampling involving different organizations

Section B was administered to gather information on the personal demographics such as age, gender, education levels, position held and years of experience in present job.

\section{Results}

The questionnaire was sent out to randomly selected respondents. Hundred and five questionnaires were distributed and 105 questionnaires were returned. However 5 questionnaires were excluded. Hence, the sample size in this study was 100 .

From the demographic profile of respondent, there were more females and $50 \%$ of the respondents belonging to the 30 to less than 40 years of age. Majority of the respondents had a bachelor's degree and a large group of these respondents were in the present job for 5 to less than 10 years. Almost $50 \%$ of the respondents are quite satisfied with their job, whereas only $3 \%$ of the respondents were not satisfied with their job.

In this research, factor analysis was used to validate whether the items in each section loaded into the expected categories. From table 1, results of factor analysis shows the four factor solution with eigenvalues greater than 1.0 were later reduced to three and the total variance explained was $55.01 \%$ of the total variance. A closer examination showed that for factor 1 the total variance explained was $21.60 \%$, for factor 2 it was $17.22 \%$ and for factor 3 explained $11.91 \%$ of the total variance.

KMO measure of sampling adequacy was 0.886 indicating sufficient intercorrelations while the Bartlett's Test of Sphericity was significant (Chi square $=3353.15, \mathrm{p}<0.000$ ). For the anti-image correlation, the level of measure of sampling adequacy for all items in the diagonal direction was greater than 0.7 which was above the minimum acceptable level.

Thus, the first factor was code of ethics, the second factor was compliance and the third factor was employee relationships. As can be seen from the original 5 continuous variables it was reduced and regrouped into only three factors after deleting the items mentioned above.

Factor analysis had reclassified the set of questionnaire thus arriving at new theoretical framework as shown in figure 2.

Means and standard deviations were obtained for the independent and dependent variables which were presented in Table 2. From the results, it may be seen that the mean of all factors (independent variables) was above average value.

To test the hypothesis multiple regression analysis was subsequently performed. Results of the multiple 
regressions are shown in table 3. Results showed that among the five independent variables, employee relationship was the most important in explaining the variance in reporting wrongdoing. These variables were also important in explaining the variance when reporting wrongdoing.

As a result employee relationships were found to have a positive influence on reporting wrongdoing. In addition, the results showed compliance mechanisms and enforcement regulations will increase reporting wrongdoing.

\section{Discussion}

\subsection{Code of ethics}

The test results of hypothesis indicate that the code of ethics does not have a positive impact on reporting wrongdoing in organizations. In comparison, the research by Embse, Desai and Desai (2004) had significant findings where non public organizations were found to be effective in applying ethical policies. Sommers (2001) also indicated that the presence of corporate codes of ethics was associated with less perceived wrongdoing in organizations, but it also resulted in the tendency to report observed unethical behaviour. Shockingly this current result is not in line with previous researches or even dose not show little similarities with existed theories, however since the previous research is undertaken in the western society, the response and perception could possibly be different compared to our local society. Moreover many peoples consider written code of ethics as an unnecessary, and just do it because the believe they should.

\subsection{Employee Relationship}

As it was expected, results shows that employee relationship have a significant positive effect on reporting wrongdoing. Rresearch by Fulmer, Gerhart and Scott (2003) indicate that positive employee relations effectively serve as an intangible and enduring asset, and can measure the firm's performance.

Near and Miceli (1995) suggest that internal and external whistle-blowing may be initiated by different triggers and auditors are more likely to whistle-blow internally than externally again emphasizing that employee relationships play an important part in organizations.

When deciding on fair treatment of employees, managers will give ethical concerns the highest priority to encourage positive working attitude. Vitell and Davis (1990) found that when top management stresses ethical behavior, employees are more satisfied with their jobs. Boyer and Webb (1992) also concluded that when codes of ethics are effectively applied, employee satisfaction increases.

\subsection{Compliance}

The results indicate that compliance is a significant variable with a $\mathrm{P}$ value of 0.071 (at the $10 \%$ level significant level). In fact the work of Smith (2006) indicates that very often organizations focus on efforts to comply with codes and guidelines without really investigating further what is really wrong or right. The tendency to comply may possibly also be due to the fact that everyone in the company agrees to adhere to regulations already set. The mechanism to report may also be in place. Organizations wanting to compete successfully, also may comply to achieve standards set such as International Standards (ISO) or adopt other best practices.

\subsection{Communication}

Our results in factor analysis indicate that items explaining communication had to be removed as they were low in loading. Findings of previous research done by Dwer and Madden (2006) where communications to new staff were found lacking but many firms had formal disciplinary procedure in place for wrong -doing instead when violations were discovered. As postulated by Wells and Spinks (1996), the code of ethics as well as upper-level management support of the code must be communicated clearly to all persons in the organization in order to have an impact on reporting wrongdoing.

The above indicates that communications may or may not influence the code of ethics in the organization depending on the mode of communication and importance attached to them. Understanding the context they are to be applied may also influence effective communication. The medium of communication is important determinant too.

\subsection{Ethical culture}

Farrell, Cobbin and Farrell (2002) indicate that the code of ethics has been used indifferent cultures and in different context. As cross cultural research has become important with companies having joint venture with foreign firms, our research undertaken had included the dimension of ethical culture as a variable, however, it was deleted after factor analysis as all three items had cross loading and could not be used for further analysis.

This variable was further explained with research undertaken by Fisher, Shirole and Bhutpar (2001). They found 
that the Indian sample mostly accepted a convention that favored the demands of family connections, whereas the UK sample accepted a convention that favored the wishes of individuals. This again reinforces the statement that ethical culture may vary across borders more so with globalization.

\section{Conclusion}

The results from in this study show that employee relationship is the most important determinant of reporting wrongdoing. Having ethical codes and guidelines alone without being effective will not benefit the organization. The findings indicate that to be effective when having code of ethics and reporting wrongdoing, the organization must invest time and effort in building good strong employee relationships.

The Malaysian government's intention to improve the Transparency Rating will in the long run restore and build more confidence among the employees for the betterment of all. As reiterated by Embse, Desai and Desai for an organization to become a genuinely ethical organization, a comprehensive approach and investment in ethical safeguards is needed and should be regarded as a dimension of decision making alongside quality standards, performance, profitability and other strategic considerations.

Organization and industry should have greater emphasis on employee relationships in handling ethical matters and reporting wrongdoing than in comparison to impact of compliance mechanisms, communication and ethical cultural. Employee relationships being an intangible asset will defiantly play a major role in giving organizations the competitive edge.

For future research on the topic of this study, it would be beneficial to examine the effect of employee relationship and communication on reporting wrongdoing.

\section{References}

Blau, P. (1964). Exchange and Power in Social Life. New York: Wiley \& Sons.

Boyer, E. P., \& Webb, T. G. (1992). Ethics and diversity: a correlation enhanced through corporate communication. IEEE Transactions on Professional Communication, 355(1), 38-43.

Donaldson, J. (1989). Key Issues in Business Ethics, London: Academic Press.

Embse, T. J., Desai, M. S., \& Desai, S. (2004). How well corporate Ethics codes and policies applied in the trenches? Information Management and computer Security, 12(2), 146-153.

Farrell, B. J., Cobbin, D. M., \& Farrell, H. M. (2002). Can codes of Ethics really produce consistent behaviors? Journal of Managerial Psychology, 17(6), 468-490.

Fisher, C. M., Shirole, R., \& Bhupatkar, A. P. (2001). Ethical Stances in Indian Management Culture. Personnel Review, 30(6), 694-711.

Fulmer, I. S., Gerhart, B., \& Scott, K. (2003). An empirical investigation of the relationship between "A great place to work" and the firm performance. Personnel Psychology, 56(4), 965-993.

Murphy, P. E. (1995). Corporate ethics statements: current status and future prospects. Journal of Business Ethics, $14,727-740$.

Near, J. P., \& Miceli, M. P. (1996). Whistle-Blowing: Myth and Reality. Journal of Management, 22(3), 507-526.

O'Dwyer, B., \& Madden, G. (2006). Ethical Codes of Conduct in Irish Companies: A Survey of Code Content and Enforcement Procedures. Journal of Business Ethics, 63(3), 217-236.

Peterson, D. K. (2003). The relationship between ethical pressure, relativistic moral beliefs and organizational commitment. Journal of Managerial Psychology, 18(6), 557-572.

Rashid, M. Z. A., Sambasivan, M., \& Rahman , A. A. (2004). The influence of organizational culture on attitudes toward organizational change. Leadership \& Organization Development Journal, 25(2), 161-179.

Sims, R.L. (2000). The relationship between employees' attitudes and conflicting expectations for lying behavior. Journal of Psychology, 134, 619-634.

Smith, E. D. (2006). Ethics in Business: Is compliance the best we can expect? [Online] Available: http://scholarsarchive.jwu.edu/grad conf/1 (February 22, 2006)

Sommer, M. J. (2001). Ethical Codes of Conduct and Organizational Context: A Study of the Relationship between Codes of Conduct, Employee Behavior and Organizational Rules. Journal of Business Ethics, 30, 185-195. 
Vitell, S. J., \& Davis, D. L. (1990). Ethical beliefs of MIS professionals: the frequency and opportunity for unethical behavior. Journal of Business Ethics, 9, 63-70.

Wells, B., \& Spinks, N. (1996). Ethics must be communicated from the top down!. Career Development International, 1(7), 28 - 30.

Table 1. Result of the Rotated Factor Analysis

\begin{tabular}{|l|c|c|c|c|}
\hline Items & Factor 1 & Factor 2 & Factor 3 & Factor 4 \\
\hline a3. written ethics policies-general & $\mathbf{. 8 6}$ & .21 & .12 & -.01 \\
a4. written ethics policies-specific & $\mathbf{. 8 2}$ & .19 & .19 & .09 \\
a2. value statement & $\mathbf{. 8 0}$ & .25 & .07 & .06 \\
a1.formal written code of ethics &. $\mathbf{7 5}$ & .25 & .14 & .13 \\
b3. ready access to ethics code/guidelines* & .49 & .32 & .42 & .15 \\
e4. common use of internal communication* & .47 & .34 & .02 & .14 \\
d2. org stress compliance-laws/regulation & .18 & .74 & .04 & -.03 \\
d4. managers compliance with regulation & .19 & .70 & .01 & -.05 \\
d3. employees exercise legal rights freely & .20 & .63 & .15 & .07 \\
c1. focus on legal rather than ethical concern** & .17 & .57 & .16 & -.55 \\
e1. expect org follow stated commitments* & .44 & .47 & .10 & -.02 \\
d1. mgrs well trained-handling legal issues* & .28 & .46 & .09 & .23 \\
e3. accurate and timely information* & .31 & .45 & .08 & .25 \\
c4. stress dignity and respect for individual & .05 & -.00 & .71 & -.07 \\
c2. fair treatment-ethical highest priority & -.01 & -.03 & .69 & -.17 \\
b1. strong, cohesive ethical culture** & .43 & .28 & .60 & -.00 \\
b2. ethics training available** & .41 & .36 & .55 & .26 \\
c3. consistent guidelines determine fairness* & .16 & .43 & .47 & .10 \\
e2. rely on unspoken, unwritten messages* & -.28 & -.12 & .13 & -.42 \\
\hline Eigenvalue & 7.35 & 2.08 & 1.67 & 1.06 \\
Variance (55.013) & 21.60 & 17.21 & 11.91 & 4.28 \\
\hline
\end{tabular}

* Low Loading - Values below 0.35 are suppressed

** Cross Loading

Table 2. Descriptive Analysis

\begin{tabular}{|l|l|l|}
\hline Variables & Mean & Std. Deviation \\
\hline Code of ethics & 3.72 & 0.87 \\
\hline Compliance & 3.57 & 0.65 \\
\hline Employee Relationships & 3.44 & 0.73 \\
\hline Reporting Wrongdoing & 3.28 & 0.62 \\
\hline
\end{tabular}

Note: All items used a 5-point Likert scale with (1=Strongly Disagree and 5=Strongly Agree) 
Table 3. Results of Multiple Regression Analysis

\begin{tabular}{|c|c|c|}
\hline \multicolumn{1}{|c|}{ Independent Variables } & $\begin{array}{c}\text { Standardized } \\
\text { Coefficients Beta }\end{array}$ & Sig. \\
\hline Ethics policies & 0.15 & 0.20 \\
\hline Compliance & 0.18 & $\mathbf{0 . 0 7 *}$ \\
\hline Employee Relationship & 0.29 & $\mathbf{0 . 0 0 * *}$ \\
\hline Sig. F & $\mathbf{0 . 0 0}$ \\
\hline F & \multicolumn{3}{|c|}{0.10} \\
\hline $\mathrm{R}^{2}$ & 0.28 \\
\hline Std. Error of Estimate & 0.53 \\
\hline Durbin-Watson & $\mathbf{1 . 7 2}$ \\
\hline Condition Index(max) & $\mathbf{1 9 . 6 8}$ \\
\hline VIF ( max $)$ & $\mathbf{1 . 8 5}$ \\
\hline
\end{tabular}

* Significant at 0.10

** Significant at 0.05

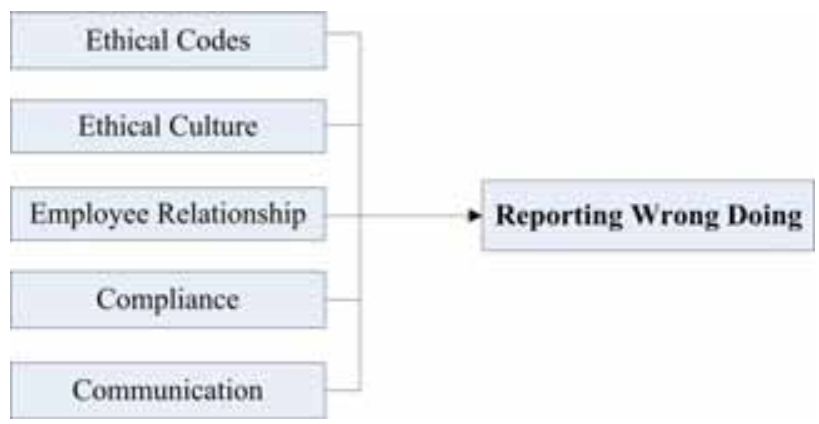

Figure 1. Theoretical framework

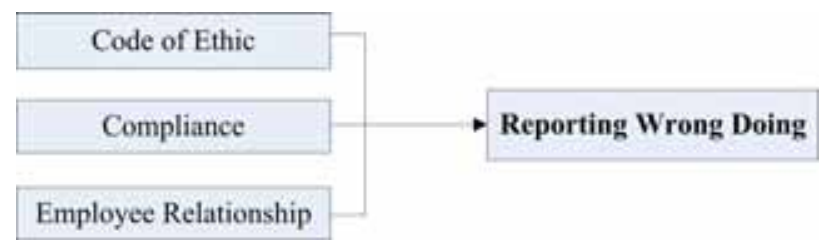

Figure 2. Revised theoretical framework 